\title{
Disruption of the Prepulse Inhibition of the Startle Reflex in Vasopressin VIb Receptor Knockout Mice: Reversal by Antipsychotic Drugs
}

\author{
Nobuaki Egashira', Akito Tanoue², Fuminori Higashihara', Hiroko Fuchigami', Kazunori Sano', Kenichi \\ Mishima', Yoshihiko Fukue', Hiroshi Nagai ${ }^{3}$, Yukio Takano ${ }^{4}$, Gozoh Tsujimoto ${ }^{5}$, Jeanne Stemmelin ${ }^{6}$, \\ Guy Griebel', Katsunori Iwasaki', Tomoaki Ikeda', Ryoji Nishimura ${ }^{3}$ and Michihiro Fujiwara*,' \\ 'Department of Neuropharmacology, Faculty of Pharmaceutical Sciences, Fukuoka University, Fukuoka, Japan; ${ }^{2}$ Department of Molecular, Cell \\ Pharmacology, National Research Institute for Child Health and Development, Tokyo, Japan; ${ }^{3}$ Department of Psychiatry, Fukuoka University \\ School of Medicine, Fukuoka University, Fukuoka, Japan; ${ }^{4}$ Department of Pharmacology, Faculty of Pharmaceutical Sciences, Fukuoka University, \\ Fukuoka, Japan; ${ }^{5}$ Department of Genomic Drug Discovery Science, Graduate School of Pharmaceutical Sciences, Kyoto University Faculty of \\ Pharmaceutical Sciences, Kyoto University, Kyoto, Japan; ${ }^{6}$ Sanofi-Aventis, Bagneux, France
}

\begin{abstract}
In the present study, we investigated whether mice lacking the arginine vasopressin (AVP) VIb receptor (VIbR) exhibit deficits of prepulse inhibition (PPI) of the startle reflex, reminiscent of the sensorimotor gating deficits observed in a large majority of schizophrenic patients. $\mathrm{VIbR}$ knockout $(\mathrm{KO})$ mice displayed significantly reduced levels of PPI of the startle reflex. In addition to PPI deficits, VIbR KO mice showed increased acoustic startle response. However, acoustic startle response was not significantly correlated to the PPI of the startle reflex in VIbR KO mice. VIbR KO mice also showed a decrease in basal levels of extracellular dopamine (DA) in the medial prefrontal cortex, which is thought to be an important brain region for PPI. Moreover, PPI deficits observed in the $\mathrm{VIbR}$ KO mice are significantly reversed by atypical antipsychotics such as risperidone and clozapine but not by a typical neuroleptic haloperidol, like in schizophrenic patients. By contrast, we did not observe any significant differences between VIbR KO mice and wild-type mice in the open-field, light/dark, elevated plus maze, and forced swimming tests. The results of the present study indicate that $\mathrm{VI}$ bR may be involved in the regulation of PPI of the startle reflex. The VIbR has been considered an important molecular target for the development of antipsychotic drugs.

Neuropsychopharmacology (2005) 30, 1996-2005. doi:I 0. I038/sj.npp. I 300784; published online I June 2005
\end{abstract}

Keywords: prepulse inhibition; vasopressin VIb receptor; antipsychotics; schizophrenia; knockout; mice

\section{INTRODUCTION}

Arginine vasopressin (AVP) is a neurohypophyseal peptide best known as an antidiuretic hormone. AVP receptors have been classified into three subtypes: V1a, V1b, and V2 receptors (Jard et al, 1987). A recent study showed that hypothalamic-pituitary-adrenal (HPA) axis activity is suppressed in AVP V1b receptor (V1bR) knockout (KO) mice under both stress and resting conditions (Tanoue et al, 2004). V1bR KO mice have also been reported to exhibit markedly reduced aggressive behavior (Wersinger

*Correspondence: Dr M Fujiwara, Department of Neuropharmacology, Faculty of Pharmaceutical Sciences, Fukuoka University, 8-19-1, Nanakuma, Fukuoka 814-0180, Japan, Tel: 81 92 87I 663I (ext. 6600), Fax: 8I 92863 0389, E-mail: mfuji@fukuoka-u.ac.jp

Received 8 November 2004; revised 12 April 2005; accepted 22 April 2005

Online publication: 27 April 2005 at http://www.acnp.org/citations/ NPP042705040528/default.pdf et al, 2002). Moreover, it has been reported that a selective V1bR antagonist produced anxiolytic- and antidepressantlike effects in rodents (Griebel et al, 2002; Serradeil-Le Gal et al, 2002) and reversed stress-induced suppression of neurogenesis in a mouse model of depression (Alonso et al, 2004). V1bR is widely distributed in the central nervous system including the cerebral cortex, hippocampus, and hypothalamus (Lolait et al, 1995; Vaccari et al, 1998), suggesting that V1bR regulates the HPA system and plays a potential role in stress-related behavior.

Recently, it has been shown that schizophrenic patients display selective impairments in response to psychosocial stress but not physical stress (Jansen et al, 2000). This suggests that HPA stress responses may be abnormal in schizophrenic patients. The HPA stress response is dependent on the type of stressor that is used (Romero and Sapolsky, 1996). The physical stimuli activate the HPA axis responses mostly via corticotropin-releasing hormone (CRH), and the psychological stimuli mostly via AVP. It has 
also been reported that baseline plasma AVP levels were lower in schizophrenic patients, and progressively increased following acute metabolic stress like 2-deoxy-Dglucose (2DG) (Elman et al, 2003). Concomitantly, it has been found that patients with schizophrenia had higher 2DG-induced plasma homovanillic acid (HVA) and 5-hydroxyindoleacetic acid (5-HIAA) levels. Thus, AVP and stress may be implicated in the course of schizophrenia.

Schizophrenia has long been associated with abnormalities in information processing and attention mechanisms (Braff, 1993; Perry and Braff, 1994). In an attempt to better understand the mechanisms underlying the physiopathology of schizophrenia, sensorimotor information gating processes have received much attention. One wellestablished method for evaluating sensory filtering is the paradigm of prepulse inhibition (PPI), which is the reduction of the startle reflex by implementation of a weak intensity prepulse immediately before the startle stimulus. The disruption of PPI in schizophrenic patients has been well described in several studies (Braff et al, 1978, 1992; Perry and Braff, 1994). In rats, the disruption of PPI occurs after acute administration of dopamine (DA) agonists (Swerdlow et al, 1986; Mansbach et al, 1988), $\mathrm{N}$-methyl-D-aspartate (NMDA) antagonists (Keith et al, 1991), or serotonin (5-HT) agonists (Sipes and Geyer, 1994). DA agonist-induced PPI deficits are reversed by both typical and atypical antipsychotics, whereas those induced by NMDA antagonists or 5-HT agonists seem to be reversed only by atypical antipsychotics (Swerdlow and Geyer, 1993; Varty and Higgins, 1995a). Thus, the drug-induced PPI deficits are differentially sensitive to various antipsychotics. In general, PPI is thought to be regulated by a prefrontocortico-limbic-striato-pallidal circuit that connects to the primary acoustic startle response pathway through mesopontine and nigral projections (Swerdlow et al, 2001). The medial prefrontal cortex plays an important role in this circuit. Manipulations that decrease DA transmission in the medial prefrontal cortex disrupt PPI (Koch and Bubser, 1994; Ellenbroek et al, 1996). In addition, the medial prefrontal cortex is thought to be involved in the PPI-disruptive effect of NMDA antagonists (Schwabe and Koch, 2004).

Recently, Brattleboro rats, in which the ability to synthesize AVP is impaired, have been reported to exhibit deficits of PPI of the startle reflex (Feifel and Priebe, 2001; Feifel et al, 2004). It is possible that central AVP may play an important role in the regulation of PPI. However, whether V1bR is involved in the regulation of PPI has remained untested. Therefore, we investigated whether mice lacking V1bR exhibit PPI deficits of the startle reflex. We also measured basal levels of extracellular DA and 5-HT in the medial prefrontal cortex in V1bR KO mice using in vivo microdialysis. Moreover, we evaluated the capacity of haloperidol (a typical antipsychotic), risperidone, and clozapine (atypical antipsychotics) to reverse the PPI deficits of the startle reflex observed in $\mathrm{V} 1 \mathrm{bR} \mathrm{KO}$ mice. In addition, we examined whether these V1bR KO mice exhibited changes in anxiety levels and depression-related emotional responses.

\section{METHODS}

\section{Animals}

In total, 139 male wild-type (WT) and 132 male V1bR KO mice $(\mathrm{V} 1 \mathrm{bR}-/-)$, which were generated by gene targeting as previously reported (Tanoue et al, 2004), were used at ages 3-7 months for all of the experiments. All mice analyzed were from F3 to F5, which carried the genetic background of 129Sv and C57Black/6J strains. They were kept under a constant light-dark cycle (light 0700-1900 hours) in a temperature-controlled $\left(23 \pm 2{ }^{\circ} \mathrm{C}\right)$ room. Experiments were conducted during the light phase between 0900 and 1700 hours. The animals had free access to food (CE-2, Crea Japan, Tokyo, Japan) and water in their home cages. All procedures regarding animal care and use were performed in compliance with the regulations established by the Experimental Animal Care and Use Committee of Fukuoka University.

\section{Drugs}

Haloperidol solution ( $5 \mathrm{mg} / \mathrm{ml}$; Serenace Injection, Dainippon Pharmaceutical Co. LTD., Osaka, Japan) was diluted with saline. Risperidone (Janssen Research Foundation, Belgium) was dissolved in saline. Clozapine (Sigma-Aldrich Co., St Louis, MO, USA) was dissolved in $0.1 \mathrm{~N} \mathrm{HCl}$ in saline and neutralized to $\mathrm{pH}$ 6-7 with $0.1 \mathrm{~N} \mathrm{NaOH}$. Haloperidol, risperidone, and clozapine were injected intraperitoneally (i.p.) $30 \mathrm{~min}$ before the test.

\section{Behavioral Test}

Open-field test. Locomotive activity in the open-field test was measured for $3 \mathrm{~min}$ as described previously (Al-Khatib et al, 1995). The activity of mice ( $n=16$ per WT mice, $n=14$ per $\mathrm{V} 1 \mathrm{bR} \mathrm{KO}$ mice) was measured by an apparatus consisting of a circular floor (diameter $=60 \mathrm{~cm}$ ) divided by thin black lines into 19 equal blocks. The floor was enclosed by a parapet (height $=50 \mathrm{~cm}$ ) with an upper opening (diameter $=90 \mathrm{~cm}$ ). The apparatus was illuminated by a $100 \mathrm{~W}$ bulb placed $80 \mathrm{~cm}$ above the center of the floor of the apparatus. The activity was measured in a sound-proof dark room under the above-described standard housing conditions.

Light/dark test. The test apparatus is based on that described by Misslin et al (1988). It consisted of two polyvinylchloride boxes $(20 \times 20 \times 14 \mathrm{~cm})$ connected by a tunnel $(5 \times 7 \times 10 \mathrm{~cm})$. One of the boxes was darkened, a desk lamp placed $20 \mathrm{~cm}$ above it lighted the other. The apparatus was equipped with infrared beams recording the following parameter for $4 \mathrm{~min}$ : time spent by mice $(n=15$ of each genotype) in the lit box.

Elevated plus maze test. The procedure is based on that described by Pellow et al (1985). The subjects for the elevated plus maze test had previously been used in the open-field test. The apparatus was made of polyvinylchloride. It was elevated to a height of $50 \mathrm{~cm}$ with two open $(25 \times 8 \mathrm{~cm})$ and two enclosed arms $(25 \times 8 \mathrm{~cm})$ arranged so that the arms of the same type were opposite each other. 
Mice ( $n=15$ per WT mice, $n=14$ per V1bR KO mice) were placed in the middle of an elevated plus maze. The time spent in the open arms was used for analysis. The test duration was $10 \mathrm{~min}$.

Forced swimming test. The procedure was a modification of that described by Porsolt et al (1977). Animals ( $n=10$ of each genotype) were placed in individual glass cylinders $(15 \mathrm{~cm}$ in height and $12 \mathrm{~cm}$ in diameter) containing water (water depth was $10 \mathrm{~cm} ; 22 \pm 1^{\circ} \mathrm{C}$ ). Two swimming sessions were conducted on the same day (an initial 6-min pretest for all mice followed by the test session). The duration of immobility was measured for a 6 -min period.

PPI of startle reflex. The startle responses were measured in an illuminated startle chamber $(39 \times 38 \times 58 \mathrm{~cm}$, SR-LAB system, San Diego Instruments, San Diego, CA, USA). It consisted of a Plexiglas cylinder ( $8 \mathrm{~cm}$ diameter, $16 \mathrm{~cm}$ long) mounted on a removable frame with a base unit. Movement of the mouse within the cylinder was detected by a piezoelectric accelerometer attached below the frame. A loudspeaker, mounted $25 \mathrm{~cm}$ above the cylinder, provided the background white noise and acoustic stimuli. The acoustic stimuli and the piezoelectric responses from the accelerometer were controlled and digitized by SR-LAB software and an interface system. The startle amplitude was defined as the average of $100 \mathrm{~ms}^{-1}$ readings collected from the beginning of the startle stimulus onset. During the session, the background noise was kept constant at $65 \mathrm{~dB}$. Animals were placed in cylinders $10 \mathrm{~min}$ prior to the initial startle stimuli and only background noise was offered during this acclimation period. To measure acoustic startle response and PPI, the five trials were: no stimulus, two types of startle stimulus only (100 and $120 \mathrm{~dB}, 20 \mathrm{~ms}$ broad band burst), and two types of startle stimulus preceded by a prepulse (a $20 \mathrm{~ms}$ broad band burst). The onset of the prepulse was separated from the startle onset by a $100 \mathrm{~ms}$ prepulse-startle interval (PSI), and the prepulse intensity used was $70 \mathrm{~dB}$. Each was repeated nine times in random order. The trials were separated by an average interval of $30 \mathrm{~s}(15-35 \mathrm{~s})$. PPI was calculated as a percentage of the pulse-alone startle amplitude using the following formula: (1-(startle amplitude following prepulse-pulse pair/startle amplitude following pulse-only) $) \times 100$. Two independent experiments (Experiments 1 and 2) were carried out. In Experiment 1, both acoustic startle response and PPI were measured in WT and V1bR KO mice $(n=18$ per WT mice, $n=16$ per V1bR KO mice). In Experiment 2, after PPI was measured, the four groups (vehicle, haloperidol, risperidone, or clozapine) were divided into WT (vehicle, $n=28$; haloperidol, $n=19$; risperidone, $n=17$; clozapine, $n=16$ ) and V1bR KO mice (vehicle, $n=27$; haloperidol, $n=17$; risperidone, $n=15$; clozapine, $n=16$ ), respectively, to calculate the effects of haloperidol, risperidone, or clozapine on PPI.

\section{Microdialysis}

Animals ( $n=18$ of each genotype) were anaesthetized with sodium pentobarbital $(50 \mathrm{mg} / \mathrm{kg}$, i.p.; Tokyo Kasei, Tokyo, Japan) and stereotaxically implanted with a guide cannula
(UI-AG-4; EICOM, Kyoto, Japan) at the medial prefrontal cortex (A: $+2.2 \mathrm{~mm}, \mathrm{~L}:-0.2 \mathrm{~mm}, \mathrm{~V}:-3.3 \mathrm{~mm}$ from the bregma), according to the atlas of Franklin and Paxinos (1997). On the day following surgery, a dialysis probe (AUI-4-02; $2.0 \mathrm{~mm}$ probe membrane, EICOM) was inserted into the guide cannula of mice and was perfused with Ringer's solution ( $147.0 \mathrm{mM} \mathrm{NaCl}, 4.0 \mathrm{mM} \mathrm{KCl}$, and $2.2 \mathrm{mM}$ $\mathrm{CaCl}_{2}$, Wako Pure Chemical Industries, Ltd, Osaka, Japan) at a constant flow rate of $2 \mu \mathrm{l} / \mathrm{min}$ using a micro syringe pump (ESP-64; EICOM). A stabilization period of $2 \mathrm{~h}$ was allowed before the experiment. Microdialysis samples $(50 \mu \mathrm{l})$ were collected at $25 \mathrm{~min}$ intervals, and the samples were then immediately injected into a high-performance liquid chromatography-electrochemical detector (HPLCECD) system for an assay of DA and 5-HT. The system (EICOM) utilized an Eicompak SC-5ODS column $(3.0 \mathrm{~mm}$ i.d. $\times 150 \mathrm{~mm}$, EICOM) that was set at a potential of $+750 \mathrm{mV}$ against an $\mathrm{Ag} / \mathrm{AgCl}$ reference electrode. The mobile phase contained $0.1 \mathrm{M}$ acetate-citrate buffer $(\mathrm{pH}$ 3.5 ), $190 \mathrm{mg} / \mathrm{l}$ sodium 1-octanesulfonate, $5 \mathrm{mg} / \mathrm{l} \mathrm{EDTA}$, and $16 \%$ methanol. The flow rate was maintained at $230 \mathrm{ml} / \mathrm{min}$. Brain DA and 5-HT release were calculated using PowerChrom (version 2.2.4, EICOM). After completion of the microdialysis experiment, the animals were anaesthetized with ether and the heads were removed. The brain was then removed, frozen, and sliced to a thickness of $40 \mu \mathrm{m}$. The position of the guide cannula in the medial prefrontal cortex site was confirmed by microscopic examination. Only data from animals in which the implantation was made at the desired site were analyzed.

\section{Statistical Analyses}

The results were expressed as means \pm SEM. The data of the open-field, light/dark, elevated plus maze, and forced swimming tests were analyzed by unpaired $t$-test. Data analyses of the acoustic startle response and PPI were evaluated for statistical significance using two-way (with repeated measures) analysis of variance (ANOVA) (factors: genotype and pulse) followed by the unpaired $t$-test to determine differences among the groups. The acoustic startle response of the drugs was analyzed by two-way ANOVA (factors: genotype and drugs) followed by Fisher's PLSD post hoc test to determine differences among the groups. The PPI of the drugs was analyzed by three-way repeated ANOVA (factors: genotype, drugs, and pulse) followed by Fisher's PLSD post hoc test to determine differences among the groups. In the brain microdialysis, the basal levels of DA and 5-HT in dialysate were expressed as pmol/50 $\mu \mathrm{l}$. The statistical analyses were performed using unpaired $t$-test. The correlation between parameters was determined by Peason's correlation coefficient test. A $p$-value of less than 0.05 was considered to be statistically significant.

\section{RESULTS}

\section{Behavioral Test}

Open-field test. There was no significant difference between V1bR KO mice and WT mice in the amount of ambulatory activity (no significant, NS, Table 1). 
Table I Performance of WT and VIbR KO Mice in Open-Field, Light/dark, Elevated Plus Maze, and Forced Swimming Tests

\begin{tabular}{lcc}
\hline Measurement & WT & VIbR KO \\
\hline $\begin{array}{l}\text { Open-field test, number of } \\
\text { ambulation }\end{array}$ & $59.3 \pm 6.7(n=16)$ & $58.4 \pm 10.8(n=14)$ \\
$\begin{array}{l}\text { Light/dark test, time in lit } \\
\text { box }(\mathrm{s})\end{array}$ & $3.73 \pm 1.87(n=15)$ & $3.06 \pm 0.7 \mid(n=15)$ \\
$\begin{array}{l}\text { Elevated plus maze test, } \\
\text { time in open arms (s) }\end{array}$ & $207.3 \pm 23.3(n=15)$ & $170.8 \pm 20.2(n=14)$ \\
$\begin{array}{l}\text { Forced swimming test, } \\
\text { immobility time (s) }\end{array}$ & $123.9 \pm 15.2(n=10)$ & $152.3 \pm 10.2(n=10)$ \\
\hline
\end{tabular}

Values represent means \pm SEM.

Light/dark test. There was no significant difference between V1bR KO mice and WT mice in the time spent by animals in the lit box (NS, Table 1).

Elevated plus maze test. There were no genotypic differences in the time spent in the open arms (NS, Table 1).

Forced swimming test. There was no difference between $\mathrm{V} 1 \mathrm{bR} \mathrm{KO}$ mice and WT mice in immobility time (NS, Table 1).

PPI. In Experiment 1, for measuring PPI by startle stimuli of 100 and $120 \mathrm{~dB}$, we found an impairment of PPI in the V1bR $\mathrm{KO}$ mice (Figure 1a). Repeated measures ANOVA revealed a significant genotype difference $\left(\mathrm{F}_{1,32}=21.9 ; p<0.001\right)$, no significant effect of pulse (NS), and no significant genotype $\times$ pulse interaction (NS) in the PPI. Post hoc analysis revealed that the PPI of the startle stimuli of 100 and $120 \mathrm{~dB}$ was lower in the V1bR KO mice than in the WT mice $(p<0.001$, respectively). On the other hand, the V1bR KO mice displayed higher levels of acoustic startle response than the WT mice (Figure 1b). Repeated measures ANOVA revealed a significant genotype difference $\left(F_{1,32}=10.22\right.$; $p<0.01)$, a significant effect of pulse $\left(F_{1,32}=8.08 ; p<0.01\right)$, and no significant genotype $\times$ pulse interaction (NS) in the acoustic startle response. Post hoc analysis revealed that startle amplitude at the pulse intensities of 100 and $120 \mathrm{~dB}$ was higher in the V1bR KO mice than in the WT mice $(p<0.01$, respectively). Post hoc analysis also revealed that there was no significant difference between 100 and $120 \mathrm{~dB}$ in the acoustic startle response of WT or V1bR KO mice (NS). In addition, the habituation of startle response displayed no difference between the two genotypes at the pulse intensities of 100 and $120 \mathrm{~dB}$ (data not shown).

There was a significant correlation between startle amplitude and PPI in WT mice $(r=-0.562, p<0.001$, Figure 2a). On the other hand, startle amplitude was not significantly correlated to PPI in V1bR KO mice $(r=-0.036$, NS, Figure 2b).

\section{Microdialysis}

The V1bR KO mice displayed lower basal levels of extracellular DA in the medial prefrontal cortex than the
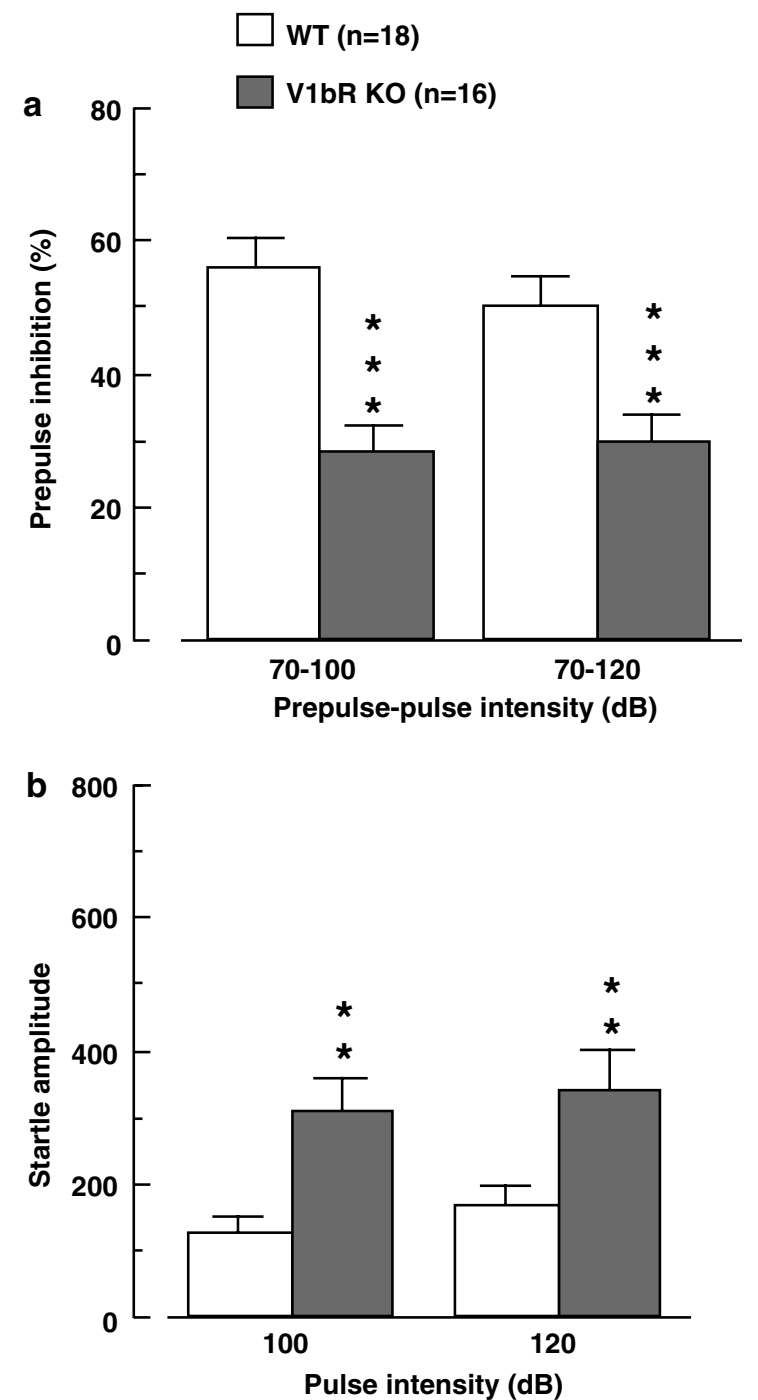

Figure I Acoustic startle response and PPI in WT and VIbR KO mice. (a) PPI: PPI of the startle reflex was lower in the VIbR KO mice than in the WT mice. (b) Acoustic startle response: VIbR KO mice displayed higher levels of acoustic startle response than the WT mice. $* * p<0.01$, **** $p<0.00$ I vs WT mice. Data are expressed as means \pm SEM.

WT mice $(p<0.05)$ (Figure 3$)$. The mean basal levels were $0.058 \pm 0.001 \mathrm{pmol} / 50 \mu \mathrm{l}$ for the WT $(n=18)$ and $0.036 \pm 0.001 \mathrm{pmol} / 50 \mu \mathrm{l}$ for the $\mathrm{V} 1 \mathrm{bR} \mathrm{KO}$ mice $(n=18)$. On the other hand, basal levels of extracellular 5-HT at the same site displayed no difference between the two genotypes (NS).

\section{Drugs}

Haloperidol. In Experiment 2, we investigated the effects of drugs on the PPI of WT and V1bR KO mice. A three-way repeated ANOVA of PPI revealed a significant genotype difference $\left(\mathrm{F}_{1,47}=19.27 ; p<0.001\right)$, no significant effect of haloperidol (NS), and no significant genotype $\times$ haloperidol interaction (NS), indicating that V1bR KO mice exhibited significant PPI deficits, and these deficits were not significantly improved by haloperidol (Figure 4). $\mathrm{V} 1 \mathrm{bR} \mathrm{KO}$ mice pretreated with haloperidol display 

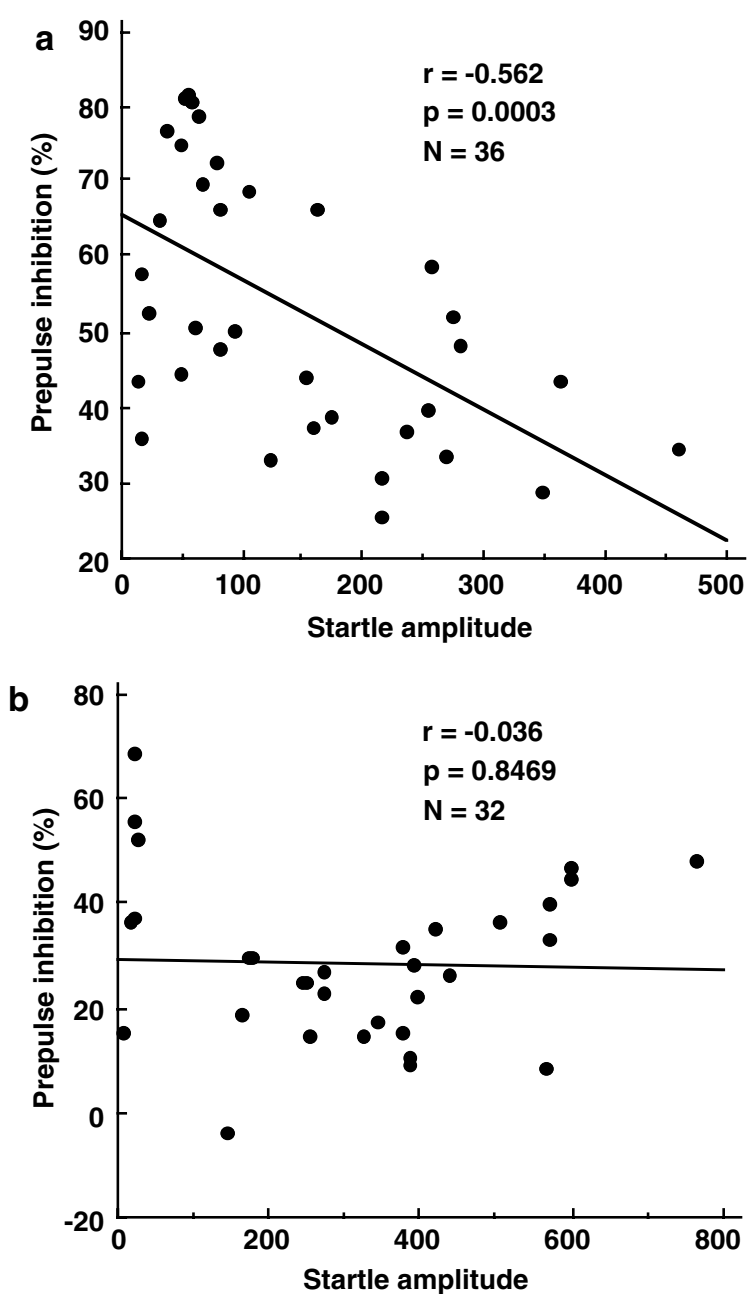

Figure 2 Correlation between acoustic startle response and PPI of the startle reflex in WT and VIbR KO mice. (a) WT mice, (b) VIbR KO mice. The Peason's correlation coefficients are shown as $r$-values.

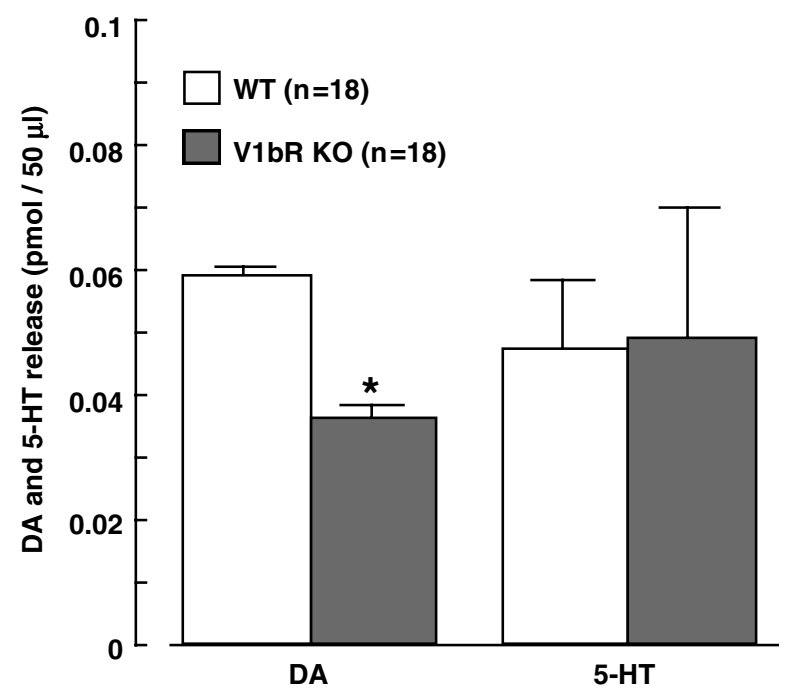

Figure 3 Basal levels of DA and 5-HT release in WT and VIbR KO mice. VIbR KO mice displayed lower basal levels of extracellular DA in the medial prefrontal cortex than WT mice. On the other hand, there were no genotypic differences in basal levels of extracellular $5-\mathrm{HT}$. * $p<0.05$ vs WT mice. Data are expressed as means \pm SEM.

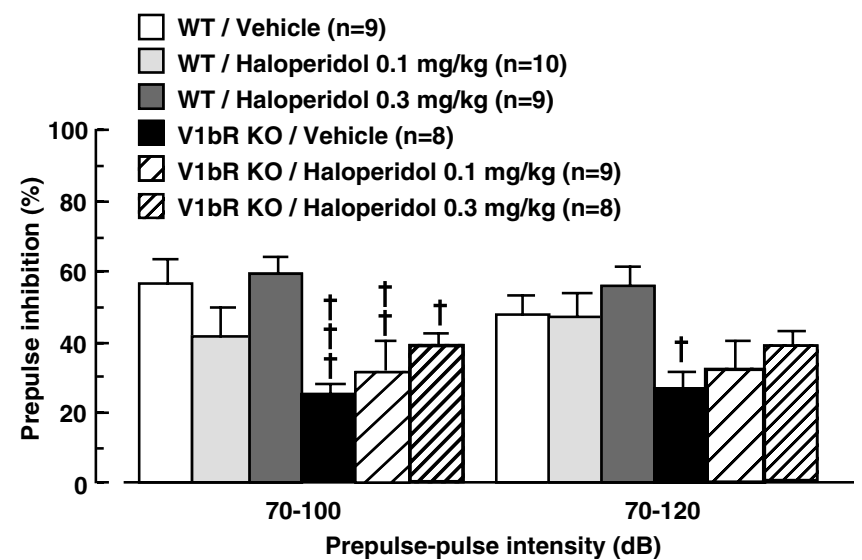

Figure 4 Effect of haloperidol on deficits of PPI of the startle reflex in VIbR KO mice. Haloperidol was injected i.p. 30 min before the test. ${ }^{\dagger} p<0.05,{ }^{\dagger \dagger} p<0.01,{ }^{\dagger \dagger \dagger} p<0.001$ vs WT/Nehicle group. Data are expressed as means \pm SEM.

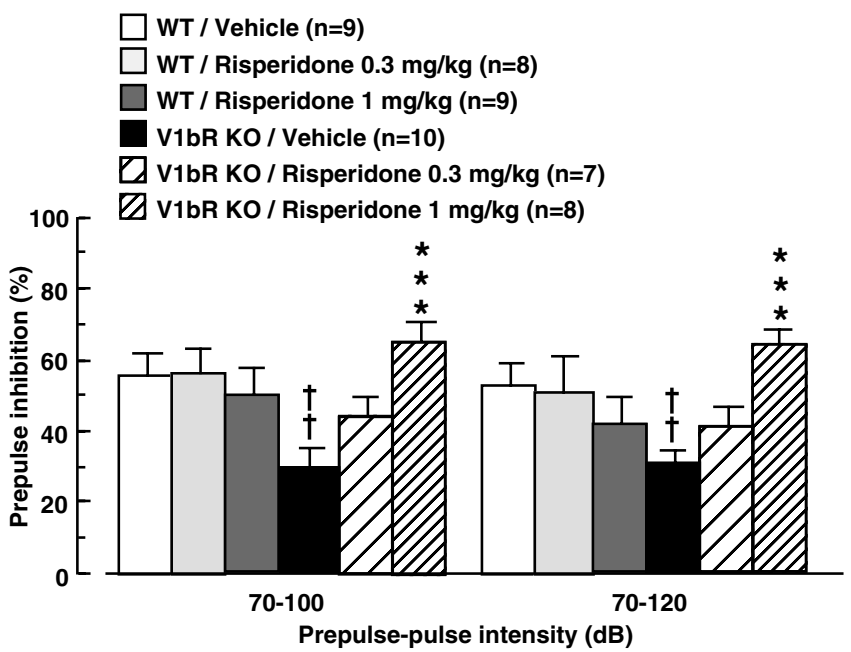

Figure 5 Effect of risperidone on deficits of PPI of the startle reflex in VIbR KO mice. Risperidone was injected i.p. 30 min before the test. ${ }^{\dagger \dagger} p<0.0$ I vs WT/Nehicle group, **** $p<0.00$ I vs VIbR KO/Vehicle group. Data are expressed as means \pm SEM.

significant deficits in PPI compared to WT mice pretreated with the vehicle in the startle stimulus of $100 \mathrm{~dB}(0.1 \mathrm{mg} / \mathrm{kg}$ : $p<0.01 ; 0.3 \mathrm{mg} / \mathrm{kg}: p<0.05)$. Moreover, V1bR KO mice, at the highest dose $(0.3 \mathrm{mg} / \mathrm{kg})$ of haloperidol, display deficits of PPI compared to WT mice receiving the same dose $(p<0.05)$. However, V1bR KO mice pretreated with haloperidol did not display any significant deficits in PPI compared to WT mice pretreated with the vehicle in the startle stimulus of $120 \mathrm{~dB}$ (NS).

Risperidone. Here also, V1bR KO mice exhibited significant PPI deficits, and these deficits were improved by risperidone (Figure 5). A three-way repeated ANOVA of PPI revealed no significant genotype difference (NS), no significant effect of risperidone (NS), and a significant genotype $\times$ risperidone interaction $\left(\mathrm{F}_{2,45}=7.47 ; p<0.01\right)$, 
indicating that risperidone had different effects on WT and V1bR KO mice. The analysis also revealed a significant effect of pulse $\left(\mathrm{F}_{1,45}=5.56 ; p<0.05\right)$. Post hoc comparisons revealed no significant effect of risperidone on the PPI of WT mice (NS). In contrast, in the V1bR KO mice, a post hoc test revealed that PPI was significantly greater in mice pretreated with risperidone at $1 \mathrm{mg} / \mathrm{kg}$ than in mice pretreated with the vehicle, in the startle stimulus of 100 and $120 \mathrm{~dB}(p<0.001$, respectively).

Clozapine. Here again, V1bR KO mice exhibited significant PPI deficits, and these deficits were improved by clozapine (Figure 6). A three-way repeated ANOVA of PPI revealed no significant genotype difference (NS), no significant effect of clozapine (NS), and a significant genotype $\times$ clozapine interaction $\left(\mathrm{F}_{2,45}=5.30 ; p<0.01\right)$, indicating that clozapine had different effects on the WT and V1bR KO mice. Post hoc comparisons revealed no significant effect of clozapine on the PPI of WT mice (NS). In contrast, in the V1bR KO mice, a post hoc test revealed that PPI was significantly greater in mice pretreated with clozapine at $3 \mathrm{mg} / \mathrm{kg}$ than in mice pretreated with the vehicle in both startle stimuli $(100 \mathrm{~dB}$ : $p<0.001,120 \mathrm{~dB}: p<0.01)$.

Acoustic startle response. Drug effects on startle response $(100 \mathrm{~dB}$ pulse alone) are seen in Figure 7.

Concerning haloperidol, a two-way ANOVA of acoustic startle response revealed a significant genotype difference $\left(\mathrm{F}_{1,47}=15.97 ; p<0.001\right)$, no significant effect of haloperidol (NS), and no significant genotype $\times$ haloperidol interaction (NS), indicating that V1bR KO mice displayed higher levels of acoustic startle response than the WT mice, and these effects were not significantly diminished by haloperidol (Figure 7a). However, V1bR KO mice pretreated with haloperidol at $0.3 \mathrm{mg} / \mathrm{kg}$ did not display any significant increase in acoustic startle response compared to WT mice pretreated with the vehicle (NS).

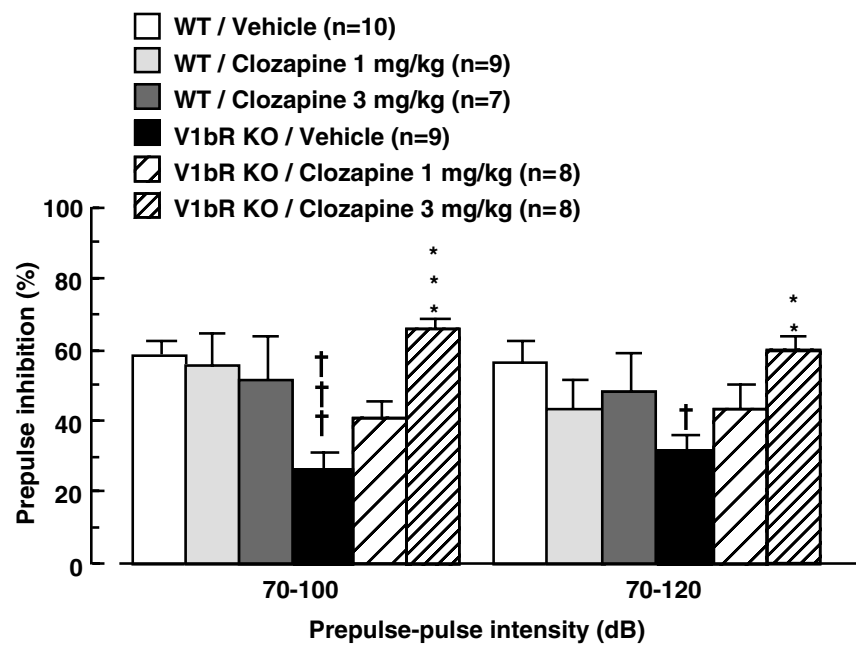

Figure 6 Effect of clozapine on deficits of PPI of the startle reflex in VIbR KO mice. Clozapine was injected i.p. $30 \mathrm{~min}$ before the test.

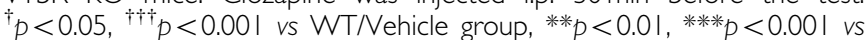
$\checkmark$ IbR KO/Vehicle group. Data are expressed as means \pm SEM.
Concerning risperidone, a two-way ANOVA of acoustic startle response revealed a significant genotype difference $\left(\mathrm{F}_{1,45}=11.62 ; p<0.01\right)$, no significant effect of risperidone $(\mathrm{NS})$, and no significant genotype $\times$ risperidone interaction (NS), indicating that V1bR KO mice displayed higher levels of acoustic startle response than the WT mice, and these effects were not significantly decreased by risperidone (Figure $7 \mathrm{~b}$ ). However, risperidone showed a dose-dependent ability to decrease acoustic startle response, and V1bR $\mathrm{KO}$ mice pretreated with risperidone did not display any
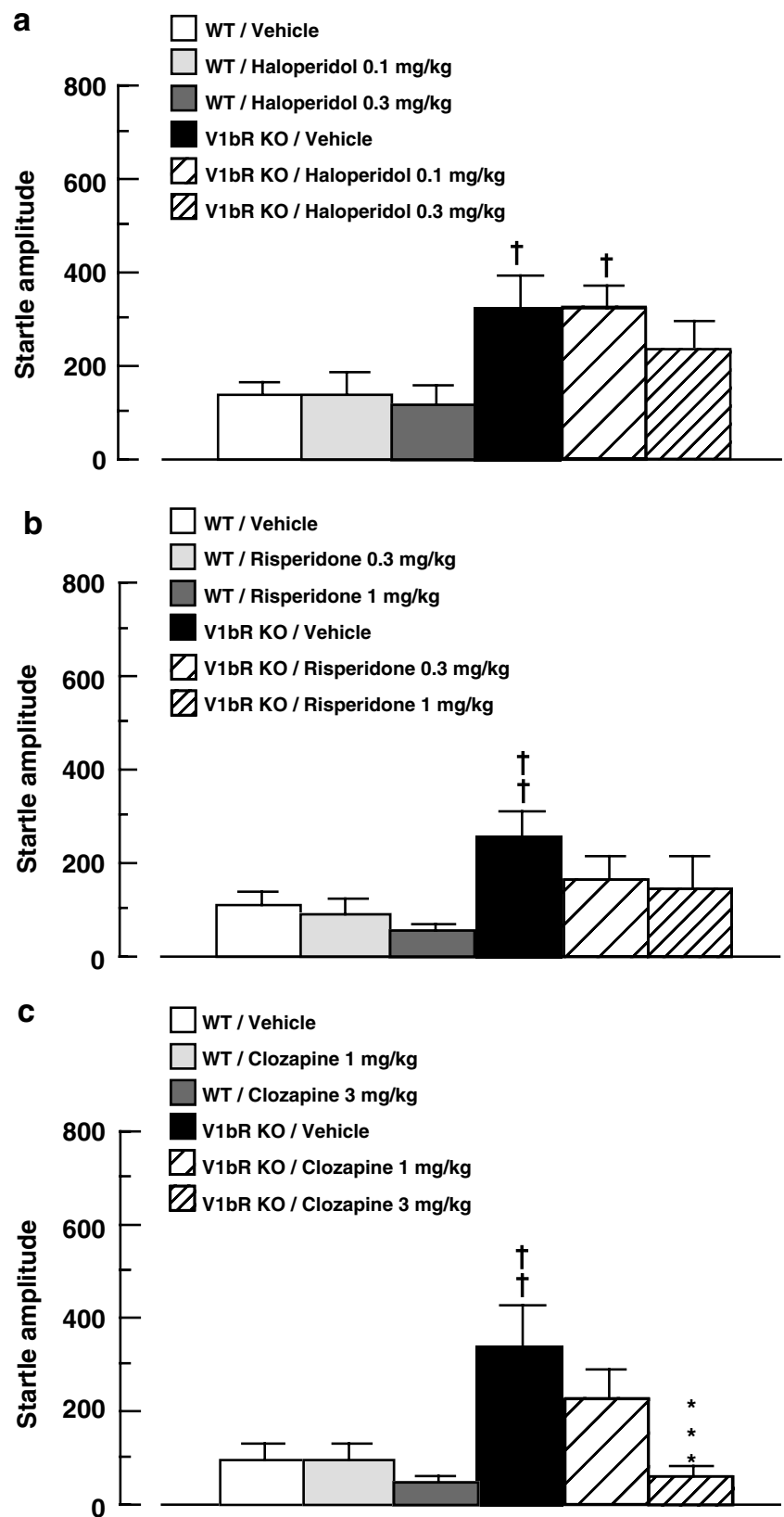

Figure 7 Effects of haloperidol, risperidone, and clozapine on acoustic startle response in the startle stimulus of $100 \mathrm{~dB}$. (a) haloperidol, (b) risperidone, and (c) clozapine. Drugs were injected i.p. 30 min before the test. ${ }^{\dagger} p<0.05,{ }^{\dagger \dagger} p<0.0$ I vs WT/Vehicle group. ${ }^{*} * * * * 0.00$ I vs VIbR KO/ Vehicle group. Data are expressed as means \pm SEM. 
significant increase in acoustic startle response compared to WT mice pretreated with the vehicle (NS).

Concerning clozapine, the V1bR KO mice displayed higher levels of acoustic startle response than the WT mice, and these effects were decreased by clozapine (Figure $7 \mathrm{c}$ ). A two-way ANOVA of acoustic startle response revealed a significant genotype difference $\left(\mathrm{F}_{1,45}=8.81 ; p<0.01\right)$, a significant effect of clozapine $\left(\mathrm{F}_{2,45}=4.67 ; p<0.05\right)$, and no significant genotype $\times$ clozapine interaction (NS), indicating that clozapine had the same effects on the WT and V1bR KO mice. Post hoc comparisons revealed no significant effects of clozapine on acoustic startle response in WT mice (NS). In contrast, in the V1bR KO mice, a post hoc test revealed that acoustic startle response was significantly lower in mice pretreated with clozapine than in mice pretreated with the vehicle (clozapine $3 \mathrm{mg} / \mathrm{kg}$ : $p<0.001$ ).

In addition, there was no significant difference between 100 and $120 \mathrm{~dB}$ in the effects of drugs on the acoustic startle response of $\mathrm{WT}$ or V1bR KO mice (data not shown).

\section{DISCUSSION}

The first major finding in the present study is that V1bR KO mice displayed significantly reduced levels of PPI of the startle reflex. In addition to PPI deficits, V1bR KO mice showed increased startle reactivity. However, this increase in startle reactivity does not seem to contribute to PPI change, for we could find no correlation between the two phenomena. On the other hand, negative correlations were observed between the startle response and PPI in WT mice. This suggests that the extent of PPI may be responsible for these observed negative correlations, but it simultaneously supports the notion that V1bR is involved in the modulation of both the startle response and its PPI. Also, the previous two studies with mice have explored differences in the startle response and PPI of multiple inbred strains. In one study, which compared 12 different mouse strains, the average startle response and PPI were not correlated between different strains (Paylor and Crawley, 1997), whereas in another study of 20 strains a positive correlation was observed between the average startle amplitude evoked by a weak auditory stimulus $(90 \mathrm{~dB})$ and PPI (Logue et al, 1997). Although the association between startle response and PPI is not currently clear, our present findings support the possibility that $\mathrm{V} 1 \mathrm{bR}$ regulates the PPI of the startle reflex. Interestingly, Brattleboro rats, in which the ability to synthesize AVP is impaired, have been reported to exhibit deficits of PPI of the startle reflex and a high startle response (Feifel and Priebe, 2001; Feifel et al, 2004). Moreover, individual startle responses and PPI in these rats were not correlated like in our current results. Therefore, V1bR might be involved in the PPI deficits in Brattleboro rats. The results of the present study also showed that the locomotive activity of $\mathrm{V} 1 \mathrm{bR} \mathrm{KO}$ mice was normal in the open-field test. Moreover, we did not observe differences between V1bR KO mice and WT mice in the light/dark, elevated plus maze, and forced swimming tests in this study. Wersinger et al (2002) also reported that V1bR $\mathrm{KO}$ mice performed normally in the open-field and elevated plus maze tests. In addition, we found that there was no difference between V1bR KO mice and WT mice in body weight ( $\mathrm{N}$ Egashira et al, unpublished data). Therefore, it is unlikely that PPI is disrupted in V1bR KO mice because of a deficit of motor function, changes of anxiety levels, or heavy body weight. These findings suggest that V1bR in particular controls PPI of the startle reflex.

The second important finding of this study is that PPI deficits observed in the V1bR KO mice are significantly reversed by atypical antipsychotics such as risperidone and clozapine, but not by a typical neuroleptics such as haloperidol. Our results are in good agreement with clinical data obtained from schizophrenic patients. Indeed, deficits in the sensorimotor gating processes are commonly shown in schizophrenic patients using PPI of the startle reflex (Braff et al, 1978, 1992; Perry and Braff, 1994; Kumari et al, 2000; Parwani et al, 2000). These PPI deficits seem to be best treated by atypical antipsychotics, as risperidone and clozapine normalized information processing functions in schizophrenic patients (Kumari et al, 1999, 2002; Kumari and Sharma, 2002), whereas this was not the case in such patients treated with typical neuroleptics (Braff et al, 1978, 1992; Bolino et al, 1992; Grillon et al, 1992). Most importantly, the PPI deficits in V1bR KO mice can be reversed by risperidone and clozapine at a dose that was without effect in WT mice. These reversals were dose dependent and exhibited great efficacy. On the other hand, the PPI deficits observed in the V1bR KO mice were not significantly reversed by haloperidol. However, V1bR KO mice pretreated with haloperidol did not display any significant deficits in PPI compared to WT mice pretreated with the vehicle in the startle stimulus of $120 \mathrm{~dB}$. Therefore, haloperidol weakly appeared to reverse these PPI deficits, which is not as strong as risperidone and clozapine. Also, the alterations in startle reactivity were reversed by clozapine, whereas they were not significantly reversed by risperidone. However, risperidone showed a dose-dependent ability to decrease acoustic startle response, and V1bR KO mice pretreated with risperidone did not display any significant increase in acoustic startle response compared to WT mice pretreated with the vehicle. Thus, risperidone appeared to decrease the acoustic startle response, if not as well as clozapine. On the other hand, haloperidol did not significantly reverse either PPI deficits or alterations of startle response in V1bR KO mice. In addition, PPI tests could not be carried out at a higher dose $(1 \mathrm{mg} / \mathrm{kg})$ of haloperidol because it caused a cataleptic state in WT and V1bR KO mice. However, V1bR KO mice pretreated with haloperidol at $0.3 \mathrm{mg} / \mathrm{kg}$ did not display any significant increase in acoustic startle response compared to WT mice pretreated with the vehicle. Like risperidone, haloperidol weakly appeared to decrease the acoustic startle response. Thus, clozapine's ability to reverse PPI deficits in V1bR KO mice is unlikely to be simply a consequence of its reduction of the startle response. Hence, it is not likely that clozapine's ability to reverse PPI deficits in V1bR KO mice is due to nonspecific effects, such as sedation, not associated with its therapeutic mechanism. Consistent with this notion, Depoortere et al (1997) concluded that clozapine's enhancement of PPI was not likely due to its sedating properties, since sedating psychotropic drugs that do not have antipsychotic properties, for example, diazepam, decrease rather than facilitate PPI. Thus, as previously stated, there is no consistent relationship between the startle 
amplitude value and the effectiveness of a given antipsychotic to restore PPI deficits (Varty and Higgins, 1995a).

The data presented in this paper show that risperidone and clozapine, but not haloperidol, significantly are able to reverse the PPI deficits observed in V1bR KO mice. Thus, to normalize PPI deficits, atypical antipsychotics such as risperidone and clozapine probably interact with the brain systems of V1bR KO mice. Interestingly, the PPI deficits observed in Brattleboro rats were also reversed by acute administration of clozapine but not by acute administration of haloperidol (Feifel et al, 2004). These findings suggest that these deficits might be particularly sensitive to some critical properties of those antipsychotic drugs. Significantly, the PPI deficits in V1bR KO mice were not reversed by haloperidol, a D2 receptor antagonist. Haloperidol's lack of efficacy indicates that excessive DA transmission is not likely to fully account for the PPI deficits seen in V1bR KO mice. On the other hand, risperidone and clozapine are potent not only as D2 receptor antagonists but also have 5-HT2A receptor antagonist properties. The PPI-disruptive effects of DOI, a 5-HT2A receptor agonist, are reversed by risperidone and clozapine but not by haloperidol (Varty and Higgins, 1995a). Also, a 5-HT2 receptor antagonist ketanserin has been reported to reverse the PPI deficits induced by an NMDA antagonist (Varty and Higgins, 1995b). However, we failed to find that ketanserin reversed the PPI deficits in V1bR KO mice in this study (N Egashira et al, unpublished data). Therefore, it is possible that risperidone and clozapine reverse PPI deficits in V1bR KO mice through a concurrent blockade of D2 and 5-HT2A receptors. More importantly, we found that V1bR KO mice showed a decrease in basal levels of extracellular DA in the medial prefrontal cortex compared to WT mice, while extracellular 5-HT in the same site showed no difference between the two genotypes. Therefore, V1bR may regulate $\mathrm{DA}$ release in the medial prefrontal cortex. The medial prefrontal cortex is thought to be an important brain region within the neuronal circuit response for PPI (Swerdlow et al, 2001). Also, dopaminergic hypofunction in the prefrontal cortex is related to the etiology of negative symptoms of schizophrenia (Davis et al, 1991). Furthermore, PPI is reduced by manipulations of dopaminergic hypofunction in the medial prefrontal cortex by infusion of 6-hydroxydopamine (6-OHDA) (Koch and Bubser, 1994) or D1 or D2 antagonists (Ellenbroek et al, 1996). These findings suggest that dopaminergic hypofunction in the medial prefrontal cortex may be involved in PPI deficits in V1bR KO mice. Hence, risperidone and clozapine may be able to increase DA release in the medial prefrontal cortex. Apparently consistent with this possibility, a recent study proposed that risperidone and clozapine could increase DA release in the medial prefrontal cortex (Hertel et al, 1996; Kuroki et al, 1999; Ichikawa et al, 2001). Moreover, these effects of atypical antipsychotics are through D2 and 5HT2A receptors blockade (Ichikawa et al, 2001). On the other hand, haloperidol has been reported to increase DA release in the nucleus accumbens but not in the medial prefrontal cortex (Kuroki et al, 1999). Given these findings, the medial prefrontal cortex may be a critical site for the deficit of PPI of the startle reflex in V1bR KO mice, and risperidone and clozapine may improve these deficits via an increase in DA release at this site.
Consistent with the previous report (Wersinger et al, 2002), we observed that V1bR KO mice did not display a change in the elevated plus maze test (animal model of anxiety). Moreover, there was no difference in the light/dark test (animal model of anxiety) and forced swimming test (animal model of depression) between V1bR KO and WT mice. The blockage of $\mathrm{V} 1 \mathrm{bR}$ by a selective antagonist induces anxiolytic- and antidepressant-like responses in rodents (Griebel et al, 2002). Therefore, the lack of behavioral modifications observed in V1bR-deficient mice could be related to unknown compensatory processes. Since KO mice are missing a receptor throughout development, numerous neurochemical and developmental changes may have occurred to compensate for the absence of the receptor. Thus, it cannot be ruled out that the observed effects are the results of compensatory adaptations in other neurotransmitter systems involved in measuring emotional response. Also, the PPI deficits in V1bR KO mice may be the result of compensatory adaptations rather than a primary consequence of the lack in the V1bR subtype.

In conclusion, our present studies show that mice lacking the V1bR exhibit PPI deficits of the startle reflex, which provides evidence that this receptor might be involved in the regulation of PPI of the startle reflex. Owing to the relevance of PPI to schizophrenia, the V1bR has been considered as an important molecular target for the development of antipsychotic drugs. The V1bR agonist has become the focus of intense interest as the first in its novel class of drugs for the treatment of schizophrenia. Also, the present study showed that the V1bR KO mice are endowed with a fair predictive validity as, like in schizophrenic patients, PPI deficits are significantly reversed by atypical antipsychotics but not by the typical neuroleptic haloperidol, and they may therefore be useful as an animal model of schizophrenia.

\section{ACKNOWLEDGEMENTS}

This work was supported in part by a Grant-in-Aid for Research on Health Sciences focusing on Drug Innovation (No. KH21005) from the Japan Health Sciences Foundation. We also thank Janssen Research Foundation, Belgium for generously donating the risperidone used in this study.

\section{REFERENCES}

Al-Khatib IMH, Dökmeci I, Fujiwara M (1995). Differential role of nucleus accumbens and caudate-putamen in mediating the effect of nomifensine and methamphetamine on ambulation and rearing of rats in the open-field test. Jpn J Pharmacol 67: 69-77.

Alonso R, Griebel G, Pavone G, Stemmelin J, Le Fur G, Soubrie P (2004). Blockade of CRF1 or V1b receptors reverses stressinduced suppression of neurogenesis in a mouse model of depression. Mol Psychiatry 9: 278-286.

Bolino F, Manna V, Di Cicco L, Di Michele V, Daneluzzo E, Rossi A et al (1992). Startle reflex habituation in functional psychoses: a controlled study. Neurosci Lett 145: 126-128.

Braff DL (1993). Information processing and attention dysfunctions in schizophrenia. Schizophr Bull 19: 233-259.

Braff DL, Grillon C, Geyer MA (1992). Gating and habituation of the startle reflex in schizophrenic patients. Arch Gen Psychiatry 49: $206-215$. 
Braff DL, Stone C, Callaway E, Geyer M, Glick I, Bali L (1978). Prestimulus effects on human startle reflex in normals and schizophrenics. Psychophysiology 15: 339-343.

Davis KL, Kahn RS, Grant K, Davidson M (1991). Dopamine in schizophrenia: a review and reconceptualization. Am J Psychiatry 148: 1474-1486.

Depoortere R, Perrault G, Sanger DJ (1997). Potentiation of prepulse inhibition of the startle reflex in rats: pharmacological evaluation of the procedure as a model for detecting antipsychotic activity. Psychopharmacology 132: 366-374.

Ellenbroek BA, Budde S, Cools AR (1996). Prepulse inhibition and latent inhibition: the role of dopamine in the medial prefrontal cortex. Neuroscience 75: 535-542.

Elman I, Lukas S, Shoaf SE, Rott D, Adler C, Breier A (2003). Effects of acute metabolic stress on the peripheral vasopressinergic system in schizophrenia. J Psychopharmacol 17: 317-323.

Feifel D, Melendez G, Shilling PD (2004). Reversal of sensorimotor gating deficits in Brattleboro rats by acute administration of clozapine and a neurotensin agonist, but not haloperidol: a potential predictive model for novel antipsychotic effects. Neuropsychopharmacology 29: 731-738.

Feifel D, Priebe K (2001). Vasopressin-deficient rats exhibit sensorimotor gating deficits that are reversed by subchronic haloperidol. Biol Psychiatry 50: 425-433.

Franklin KBJ, Paxinos G (1997). The Mouse Brain in Stereotaxic Coordinate. Academic Press, Inc.: San Diego.

Griebel G, Simiand J, Serradeil-Le Gal C, Wagnon J, Pascal M, Scatton B et al (2002). Anxiolytic- and antidepressant-like effects of the non-peptide vasopressin $\mathrm{V} 1 \mathrm{~b}$ receptor antagonist, SSR149415, suggest an innovative approach for the treatment of stress-related disorders. Proc Natl Acad Sci USA 99: 63706375.

Grillon C, Ameli R, Charney DS, Krystal J, Braff D (1992). Startle gating deficits occur across prepulse intensities in schizophrenic patients. Biol Psychiatry 32: 939-943.

Hertel P, Nomikos GG, Iurlo M, Svensson TH (1996). Risperidone: regional effects in vivo on release and metabolism of dopamine and serotonin in the rat brain. Psychopharmacology 124: 74-86.

Ichikawa J, Ishii $\mathrm{H}$, Bonaccorso S, Fowler WL, O'Laughlin IA, Meltzer HY (2001). 5- $\mathrm{HT}_{2 \mathrm{~A}}$ and $\mathrm{D}_{2}$ receptor blockade increase cortical DA release via 5-HT1A receptor activation: a possible mechanism of atypical antipsychotic-induced cortical dopamine release. J Neurochem 76: 1521-1531.

Jansen LM, Gispen-de Wied CC, Kahn RS (2000). Selective impairments in the stress response in schizophrenic patients. Psychopharmacology 149: 319-325.

Jard S, Barberis C, Audigier S, Tribollet E (1987). Neurohypophyseal hormone receptor systems in brain and periphery. Prog Brain Res 72: 173-187.

Keith VA, Mansbach RS, Geyer MA (1991). Failure of haloperidol to block the effects of phencyclidine and dizocilpine on prepulse inhibition of startle. Biol Psychiatry 30: 557-566.

Koch M, Bubser M (1994). Deficient sensorimotor gating after 6-hydroxydopamine lesion of the rat medial prefrontal cortex is reversed by haloperidol. Eur J Neurosci 6: 1837-1845.

Kumari V, Sharma T (2002). Effects of typical and atypical antipsychotics on prepulse inhibition in schizophrenia: a critical evaluation of current evidence and directions for future research. Psychopharmacology 162: 97-101.

Kumari V, Soni W, Mathew VM, Sharma T (2000). Prepulse inhibition of the startle response in men with schizophrenia: effects of age of onset of illness, symptoms, and medication. Arch Gen Psychiatry 57: 609-614.

Kumari V, Soni W, Sharma T (1999). Normalization of information processing deficits in schizophrenia with clozapine. $A m J$ Psychiatry 156: 1046-1051.
Kumari V, Soni W, Sharma T (2002). Prepulse inhibition of the startle response in risperidone-treated patients: comparison with typical antipsychotics. Schizophr Res 55: 139-146.

Kuroki T, Meltzer HY, Ichikawa J (1999). Effects of antipsychotic drugs on extracellular dopamine levels in rat medial prefrontal cortex and nucleus accumbens. J Pharmacol Exp Ther 288: 774-781.

Logue SF, Owen EH, Rasmussen DL, Wehner JM (1997). Assessment of locomotor activity, acoustic and tactile startle, and prepulse inhibition of startle in inbred mouse strains and F1 hybrids: implications of genetic background for single gene and quantitative trait loci analyses. Neuroscience 80: $1075-1086$.

Lolait SJ, O'Carroll AM, Mahan LC, Felder CC, Button DC, Young III WS et al (1995). Extrapituitary expression of the rat V1b vasopressin receptor gene. Proc Natl Acad Sci USA 92: 6783-6787.

Mansbach RS, Geyer MA, Braff DL (1988). Dopaminergic stimulation disrupts sensorimotor gating in the rat. Psychopharmacology 94: 507-514.

Misslin R, Belzung C, Vogel E (1988). Interaction of RO 15-4513 and ethanol on the behaviour of mice: antagonistic or additive effects? Psychopharmacology (Berl) 94: 392-396.

Parwani A, Duncan EJ, Bartlett E, Madonick SH, Efferen TR, Rajan $\mathrm{R}$ et al (2000). Impaired prepulse inhibition of acoustic startle in schizophrenia. Biol Psychiatry 47: 662-669.

Paylor R, Crawley JN (1997). Inbred strain differences in prepulse inhibition of the mouse startle response. Psychopharmacology 132: $169-180$.

Pellow S, Chopin P, File SE, Briley M (1985). Validation of open: closed arm entries in an elevated plus-maze as a measure of anxiety in the rat. $J$ Neurosci Methods 14: 149-167.

Perry W, Braff DL (1994). Information-processing deficits and thought disorder in schizophrenia. Am J Psychiatry 151: 363-367.

Porsolt RD, Le Pichon M, Jalfre M (1977). Depression: a new animal model sensitive to antidepressant treatments. Nature 266 : 730-732.

Romero LM, Sapolsky RM (1996). Patterns of ACTH secretagog secretion in response to psychological stimuli. J Neuroendocrinol 8: $243-258$

Schwabe K, Koch M (2004). Role of the medial prefrontal cortex in $\mathrm{N}$-methyl-D-aspartate receptor antagonist induced sensorimotor gating deficit in rats. Neurosci Lett 355: 5-8.

Serradeil-Le Gal C, Wagnon J, Simiand J, Griebel G, Lacour C, Guillon $G$ et al (2002). Characterization of (2S, 4R)-1-[5chloro-1-[(2, 4-dimethoxyphenyl)sulfonyl]-3-(2-methoxy-phenyl)2-oxo-2, 3-dihydro-1 $H$-indol-3-yl]-4-hydroxy- $N, \quad N$-dimethyl2-pyrrolidine carboxamide (SSR149415), a selective and orally active vasopressin V1b receptor antagonist. J Pharmacol Exp Ther 300: $1122-1130$.

Sipes TA, Geyer MA (1994). Multiple serotonin receptor subtypes modulate prepulse inhibition of the startle response in rats. Neuropharmacology 33: 441-448.

Swerdlow NR, Braff DL, Geyer MA, Koob GF (1986). Central dopamine hyperactivity in rats mimics abnormal acoustic startle response in schizophrenics. Biol Psychiatry 21: 23-33.

Swerdlow NR, Geyer MA (1993). Clozapine and haloperidol in an animal model of sensorimotor gating deficits in schizophrenia. Pharmacol Biochem Behav 44: 741-744.

Swerdlow NR, Geyer MA, Braff DL (2001). Neural circuit regulation of prepulse inhibition of startle in the rat: current knowledge and future challenges. Psychopharmacology 156: 194-215.

Tanoue A, Ito S, Honda K, Oshikawa S, Kitagawa Y, Koshimizu T et al (2004). The Vasopressin V1b receptor critically regulates hypothalamic-pituitary-adrenal axis activity under both stress and resting conditions. J Clin Invest 113: 302-309. 
Vaccari C, Lolait SJ, Ostrowski NL (1998). Comparative distribution of vasopressin V1b and oxytocin receptor messenger ribonucleic acids in brain. Endocrinology 139: 5015-5033.

Varty GB, Higgins GA (1995a). Examination of drug-induced and isolation-induced disruptions of prepulse inhibition as models to screen antipsychotic drugs. Psychopharmacology 122: $15-26$.
Varty GB, Higgins GA (1995b). Reversal of dizocilpine-induced disruption of prepulse inhibition of an acoustic startle response by the 5-HT2 receptor antagonist ketanserin. Eur J Pharmacol 287: 201-205.

Wersinger SR, Ginns EI, O'Carroll A-M, Lolait SJ, Young III WS (2002). Vasopressin V1b receptor knockout reduces aggressive behavior in male mice. Mol Psychiatry 7: 975-984. 